\title{
Biological and Structural Mechanisms of Disease Development and Resistance in Chili Pepper Infected with the Root-knot Nematode
}

\author{
Hyo Sun Moon ${ }^{1}$, Zakaullah Khan ${ }^{2}$, Sang Gyu Kim ${ }^{1}$, Seon-Hye Son ${ }^{1}$ and Young Ho Kim ${ }^{1 *}$ \\ ${ }^{1}$ Department of Agricultural Biotechnology, Seoul National University, Seoul 151-921, Korea \\ ${ }^{2}$ Germplasm Evaluation Division, National Bureau of Plant Genetic Resources, New Delhi, 110 012, India \\ (Received on November 24, 2009; Accepted on January 6, 2010)
}

Biological and structural mechanisms of the nematode disease development in chili pepper caused by the rootknot nematode, Meloidogyne incognita, were investigated. Out of 39 chili pepper cultivars/lines tested, six were found resistant, while 33 were susceptible to $M$. incognita, of which a susceptible cultivar Chilseongcho and three resistant cultivar/lines CM334, 02G132 and $03 G 53$ with different resistance degrees were selected for microscopic studies on the disease development. Gall formation was greatly reduced in the resistant cultivars/ lines. Nematode penetration occurred both in the susceptible and resistant chili pepper roots; however, the penetration rates were significantly lowered in the three resistant peppers compared to the susceptible pepper cv. Chilseongcho. In the susceptible pepper, giant cells were extensively formed with no discernible necrosis around the nematode feeding sites. In the highly resistant pepper cultivar CM334, no giant cell was formed, but extensive necrosis formation was observed around the penetrating nematodes. In the other two resistant pepper lines (02G132 and 03G53), both giant cells and prominent necroses were formed, and the necrotic responses appeared to inhibit the further development of giant cells or accelerate their early degeneration. Although the nematode penetration was retarded significantly in the resistant cultivar/lines, all of the above results suggest that the disease resistance of pepper may be related to post-infectional defense mechanisms (nematode growth and development) more than pre-infectional ones (penetration and establishment). Variations in structural modifications in the resistant cultivar/lines may reflect their genetic differences related to the nematode resistance.

Keywords : giant cell formation, Meloidogyne incognita, necrosis, penetration, resistance

The root-knot nematodes (RKN), Meloidogyne spp., are sedentary endoparasites damaging a variety of agricultural crops, causing an estimated US $\$ 100$ billion loss/year

\footnotetext{
*Corresponding author.

Phone) +82-2-880-4675, FAX) +82-2-873-2317

E-mail)yhokim@snu.ac.kr
}

worldwide (Oka et al., 2000). They are important pathogens of several Solanaceous crops, especially red pepper, potato and tomato (Barker, 1998; Sasser, 1977). Other than chemical methods with fumigant and non-fumigant nematicides, use of resistant cultivars is considered one of the most effective and environmentally-safe alternatives (Hartman and Sasser, 1985).

The root-knot nematodes penetrate roots as second-stage juveniles (J2) to establish a feeding site usually within the pericycle and vascular tissues and form giant cells soon after their infection (Agrios, 2005). Galls are formed due to hyperplasia of root cells around giant cells. Intensive root galling seriously reduces root efficiency and often results in permanent wilting, premature defoliation, and eventually plant death. When susceptible plants are infected with RKN, cell enlargement accompanied by nuclear division without cytokinesis gives rise to large, multinucleate giant cells; in contrast, resistance plants to RKN are characterized by hypersensitive reaction (HR) (localized cell necrosis around the nematode head) (Kaplan and Keen, 1980). RKN juveniles surrounded by necrotic cells fail to develop, and die. These responses can occur at early infection stages, thereby preventing the nematode penetration and migration (Paulson and Webster, 1972) or at later stages, inhibiting the development of giant cells and suppressing the nematode development and multiplication (Pontier et al., 1999).

In chili pepper, however, little study has been conducted about the disease development of the root-knot nematode as yet. Therefore, this study aims to examine mechanisms of resistance to the root-knot nematode (Meloidogyne incognita) in pepper cultivars and lines selected through resistance screening experiments in relation to the nematode disease cycle from penetration through development and reproduction with the aid of microscopic techniques.

\section{Materials and Methods}

Preparation of nematode inoculum. Four-week-old pepper plants (Capsicum annuum cv. Bugang) were inoculated with the second-stage juveniles (J2) of Meloidogyne incognita that have been used previously in root-knot nematode 
experiments (Khan et al., 2008). Sixty days after inoculation, plants were carefully uprooted from pots and the root systems were gently washed with tap water to remove adhering soil. Egg masses of $M$. incognita were handpicked with the help of the forceps. The eggs were placed on Baermann funnel for three days to allow $\mathrm{J} 2$ to hatch out (Southey, 1986).

Plant materials. Thirty-nine cultivars/lines of chili pepper kindly provided by Dr. B. D. Kim, Department of Horticulture Science, Seoul National University, were used in the experiments. Seeds of the chili pepper cultivars/lines were germinated in Petri plates at $28^{\circ} \mathrm{C}$ for 2 days and sown in $4.5 \times 4.5 \mathrm{~cm}$ plastic cell trays filled with potting soil sterilized at $121^{\circ} \mathrm{C}$ and $15 \mathrm{psi}$. Seeded trays were kept in growth chamber at temperature of $25^{\circ} \mathrm{C}$ for four weeks, and watered daily.

Host status of chili pepper cultivars/lines for $M$. incognita. Four-week-old chili pepper plants (39 cultivars/lines) were transplanted individually into 6 -cm-diameter plastic pots containing sterilized sand and potting soil mixture. Each plant was inoculated with 1,000 J2 of M. incognita dispensed in $10 \mathrm{ml}$ of water around the root zone with a pipette, after which the pots were lightly watered. Each cultivar/line was replicated five times. Pots were arranged in randomized complete block design on greenhouse benches maintained at $25 \pm 2^{\circ} \mathrm{C}$. Forty-five days after $M$. incognita inoculation, plants were carefully uprooted from pots, the root systems were gently washed with tap water to remove adhering soil, and the roots were examined with naked eyes for root galls formed on each rootlet. Root galls per plant root system were counted and a gall index (GI) of $0-5$ was assigned $(0=$ no gall, $1=1-2,2=3-10,3=11-30,4=$ $31-100,5=>100$ galls per root system) (Taylor and Sasser, 1978). Host responses of chili pepper cultivars/lines were determined using GI to be regarded as highly resistant (HR) when $\mathrm{GI} \leq 0.1$, resistant (R) GI $\leq 2.0$, and susceptible (S) when $\mathrm{GI}>2.0$.

Examination of nematode penetration, development and reproduction. In the above experiment, one susceptible pepper cultivar (cv. Chilseongcho) and three resistant pepper lines (02G132, 03G53 and CM334) were selected for further studies. Four-week-old chili pepper plants were transplanted individually into 6-cm diameter plastic pots containing sterilized sand and potting soil mixture. Each plant was inoculated with a water suspension containing $1,000 \mathrm{~J} 2$ of M. incognita. Each cultivar/line was replicated five times. At 2, 5, 10, and 15 days after $\mathrm{J} 2$ inoculation, the seedlings were removed from pots, and root systems were washed carefully and fixed with FAA (formalin-acetic acidalcohol) (formalin : glacial acetic acid : 95\% ethanol : distilled water $=2: 1: 10: 7$ ) overnight. The fixed roots were cleared in $2 \%$ sodium hypochlorite for $10 \mathrm{~min}$ and stained with $0.07 \%$ bromophenol blue in $50 \%$ ethanol for $8 \mathrm{~h}$, and rinsed in 50\% ethanol (Kim et al., 1986). The number of nematodes in infection sites in root tissues was counted using a stereomicroscope.

For examining the nematode reproduction, plants were carefully uprooted from pots forty-five days after $M$. incognita inoculation, and the root systems were gently washed with tap water to remove adhering soil. Nematode egg masses formed on rootlets were examined with naked eyes.

Structural changes of pepper root tissues infected with M. incognita. The four pepper cultivars/lines were planted and inoculated with $\mathrm{J} 2$ as described above. Plants were uprooted from pots at 2, 5 and 10 days after inoculation. Infected pepper root specimens were fixed with Karnovsky's fixative consisting of $2 \%(\mathrm{v} / \mathrm{v})$ glutaraldehyde and $2 \%(\mathrm{v} / \mathrm{v})$ paraformaldehyde in $0.05 \mathrm{M}$ cacodylate buffer ( $\mathrm{pH}$ 7.2) for $4 \mathrm{~h}$. The root specimens were washed in $0.05 \mathrm{M}$ cacodylate buffer ( $\mathrm{pH}$ 7.2) for three times for $15 \mathrm{~min}$ each, and postfixed in $1 \%$ osmium tetroxide in the same buffer for $2 \mathrm{~h}$ (kept at $4^{\circ} \mathrm{C}$ in a refrigerator). They were washed briefly with distilled water for 1-2 min, and en block stained in $0.5 \%$ uranyl acetate overnight at $4{ }^{\circ} \mathrm{C}$ in a refrigerator. Then the specimens were dehydrated in an ethanol series of 30 , $50,70,80,90 \%$ and finally three times in $100 \%$ ethanol for $10 \mathrm{~min}$ each. The specimens were further treated with two changes of propylene oxide each for $15 \mathrm{~min}$, and embedded in Spurr's epoxy resin (Spurr, 1969), followed by polymerization at $70^{\circ} \mathrm{C}$ for $8 \mathrm{~h}$. Sections were made $500-700 \mathrm{~nm}$ in thickness with a glass knife on an ultramicrotome (MT$\mathrm{X}, \mathrm{RMC}$, Tucson, AZ, USA). The sections were stained with $1 \%$ toluidine blue $\mathrm{O}$ in $2 \%$ sodium tetraborate and observed under a light microscope (Axiophot, Carl Zeiss, Germany).

\section{Results}

Host status of chili pepper cultivars/lines for $M$. incognita. Out of 39 chili pepper cultivars/lines screened for susceptibility and resistance to M. incognita, 33 cultivars/ lines including $\mathrm{cv}$. Chilseongcho and others (data not shown) were determined to be susceptible because numerous large root galls were formed with GI $>2.0$ in all of these peppers. On the other hand, almost no gall was formed with $\mathrm{GI}<1.0$ in 6 pepper cultivar/lines; Ls. 02G132, 03G62, 04G8, and 99G198 determined to be resistant and line L. 03G53 and cv. CM334 to be highly resistant (Table 1). 
Table 1. Host status of chili pepper cultivars/lines for Meloidogyne incognita, examined 45 days after inoculation of 1000 juveniles (J2) per plant

\begin{tabular}{lcc}
\hline \hline Cultivar/line & $\mathrm{GI}^{\mathrm{a}}$ & Host status $^{\mathrm{b}}$ \\
\hline Chilseongcho & $4.4 \pm 0.5^{\mathrm{c}}$ & $\mathrm{S}$ \\
02G132 & $0.2 \pm 0.4$ & $\mathrm{R}$ \\
03G62 & $0.4 \pm 0.5$ & $\mathrm{R}$ \\
04G8 & $0.4 \pm 0.9$ & $\mathrm{R}$ \\
99G198 & $0.8 \pm 0.8$ & $\mathrm{R}$ \\
03G53 & $0.0 \pm 0.0$ & $\mathrm{HR}$ \\
CM334 & $0.0 \pm 0.0$ & $\mathrm{HR}$
\end{tabular}

${ }^{\mathrm{a}} \mathrm{GI}$ (gall index): A scale of 0-5 was used as: $0=$ no gall, $1=1-2,2=3$ $-10,3=11-30,4=31-100,5=>100$ galls per root system (Taylor and Sasser, 1978).

${ }^{b}$ Host responses of chili pepper cultivars/lines were determined using root gall index (GI) to be regarded as highly resistant (HR) when $\mathrm{GI} \leq 0.1$, resistant $(\mathrm{R})$ when $\mathrm{GI} \leq 2$, but susceptible (S) when $\mathrm{GI}>2$ (Sasser et al., 1984).

${ }^{c}$ Means and standard deviations of five replicates

\section{Nematode penetration, development and reproduction.} In the above experiment, one susceptible cultivar Chilseongcho and three resistant cultivar/lines CM334, 02G132 and $03 \mathrm{G} 53$ were selected for nematode penetration and reproduction experiments. At 2, 5, 10 and 15 days after inoculation (DAI), nematode penetrations were examined by counting the stained $\mathrm{J} 2$ in the roots of susceptible and resistant pepper cultivar/lines (Table 2). A significant difference $(\mathrm{P}>0.05)$ was observed in nematode penetration between susceptible and resistant pepper cultivars/lines, and the penetration rates in the resistant peppers were also lowered significantly in order of CM334, 02G132 and 03G53 (Table 2). This difference increased substantially with passage of time after inoculation. Up to 10 and 15 days after inoculation, 21.5 and $23.4 \%$ of the inoculum penetrated the roots of the Chilseongcho pepper, whereas less than $4 \%$ of $\mathrm{J} 2$ penetrated the roots of CM334, 02G132 and 03G53. For the nematode reproduction, the number of egg

Table 2. Nematode penetration and egg mass formation in the susceptible and resistant pepper cultivars/lines

\begin{tabular}{lcrrrc}
\hline \hline Cultivar/line & \multicolumn{4}{c}{$\begin{array}{c}\text { Nematode penetration rate (\%) } \\
\text { at DAI }\end{array}$} & $\begin{array}{c}\text { No. of egg } \\
\text { masses per root } \\
45 \text { DAI }\end{array}$ \\
\cline { 2 - 5 } & \multicolumn{1}{c}{5} & \multicolumn{1}{c}{10} & 15 & \\
\hline Chilseongcho & $6.2 \mathrm{a}^{\mathrm{b}}$ & $17.2 \mathrm{a}$ & $21.5 \mathrm{a}$ & $23.4 \mathrm{a}$ & $317.6 \mathrm{a}$ \\
CM334 & $1.3 \mathrm{~b}$ & $3.2 \mathrm{~b}$ & $3.5 \mathrm{~b}$ & $3.1 \mathrm{~b}$ & $0.0 \mathrm{~b}$ \\
$02 \mathrm{G} 132$ & $0.6 \mathrm{c}$ & $2.0 \mathrm{c}$ & $2.4 \mathrm{c}$ & $2.0 . \mathrm{c}$ & $0.0 \mathrm{~b}$ \\
$03 \mathrm{G} 53$ & $0.2 \mathrm{~d}$ & $0.8 \mathrm{~d}$ & $1.1 \mathrm{~d}$ & $0.9 \mathrm{~d}$ & $0.0 \mathrm{~b}$ \\
\hline
\end{tabular}

"Examined respective days after inoculation with 1,000 second-stage juveniles (J2) of Meloidogyne incognita. DAI: days after inoculation. ${ }^{a}$ Values are means of 5 replications.

${ }^{\mathrm{b}}$ Means followed by the same letters are not significantly different at $\mathrm{P}=0.05$ by Duncan's multiple range test. masses observed in the susceptible pepper (cv. Chilseongcho) at 45 days after inoculation comprised $31.8 \%$ of the number of $\mathrm{J} 2$ inoculated, but no egg masses were found in all the resistant pepper cultivar/lines tested.

Structural changes of pepper root tissues infected with M. incognita. A time course study to determine the structural changes in susceptible (cv. Chilseongcho) and resistant (cv. CM334, Ls. 02G132 and 03G53) peppers was made at 2, 5, and 10 days after inoculation (DAI) with $M$. incognita. At 2 DAI, sections of infected roots of Chilseongcho (S), CM334 (HR), 02G132 (R) and 03G53 (HR) showed that plant responses have already occurred in the infected root tissues. In cv. Chilseongcho, most of the J2 entered the roots and moved intercellularly through the root tip and elongation zone, in which modified cells were formed adjacent to the infecting nematodes (Fig. 1A). In CM334, 02G132 and 03G53, a few J2 entered the roots but most of the $\mathrm{J} 2$ were surrounded by necrotic cells (Fig. 1B, $\mathrm{C}$ and $\mathrm{D})$. The tissues comprising the necrotic cells were stained blue with toluidine blue $\mathrm{O}$, indicating the accumulation of phenolic compounds, which may be related to plant defense mechanisms. At 5 DAI, the sectioned root tissues of cv. Chilseongcho showed giant cells formed extensively in the stellar region, characterized by hypertrophied and dense cytoplasm with no apparent central vacuoles (Fig. 2A). In CM334, 02G132 and 03G53, no giant cells were formed, but prominent necroses were formed around the infecting nematodes especially in 02G132 and 03G53 (Fig. 2B, C, D). At 10 DAI, very large giant cells were extensively formed in the susceptible pepper Chilseongcho, surrounding the infecting nematodes
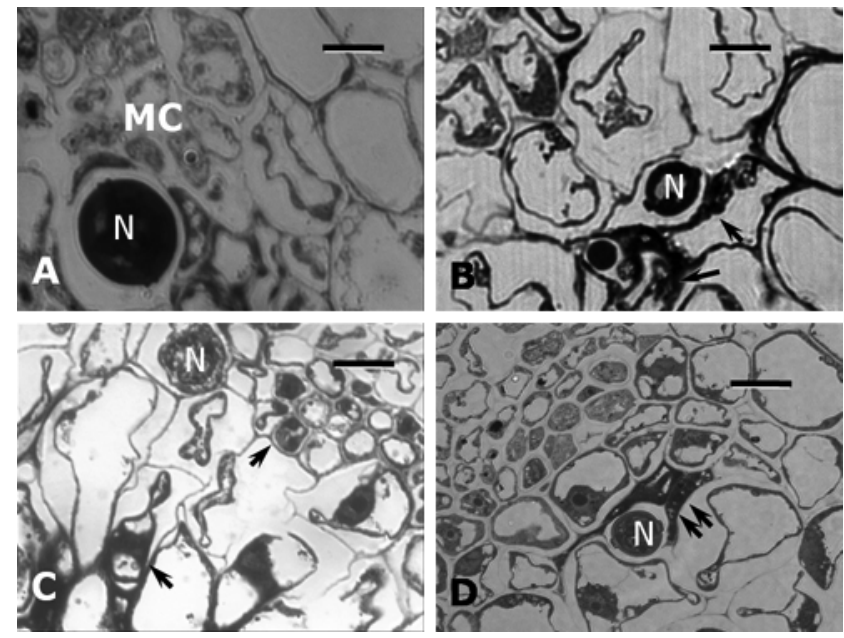

Fig. 1. Light micrographs of susceptible and resistant responses in roots of chili peppers (A: Chilseongcho, B: CM334, C: 02G132, D: 03G53) infected with Meloidogyne incognita at 2 days after inoculation. N: infecting nematodes, Arrows: necrotic areas, MC: modified cells. Bars $=20 \mu \mathrm{m}$. 

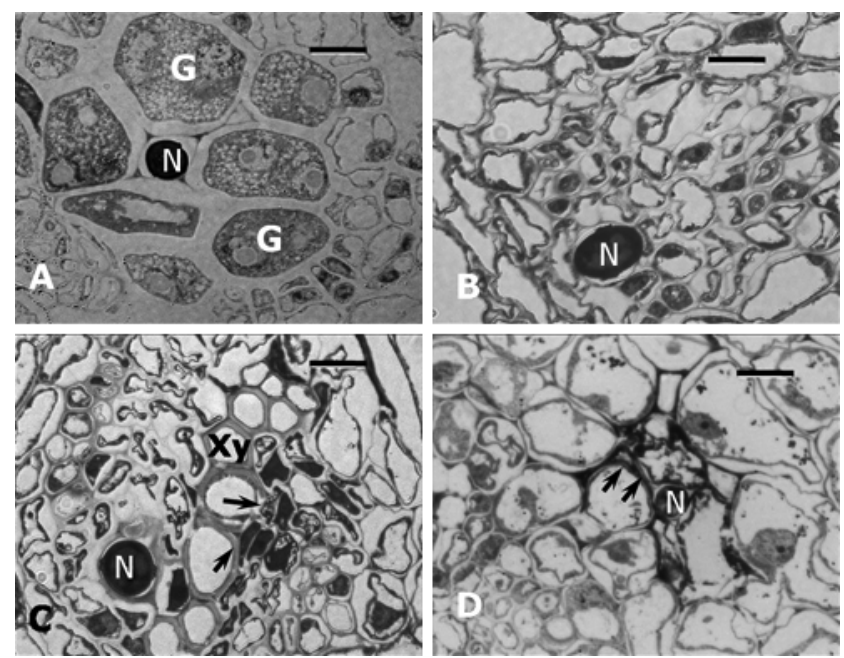

Fig. 2. Light micrographs of susceptible and resistant responses in chili pepper (A: Chilseongcho, B: CM334, C: 02G132, D: 03G53) infected with Meloidogyne incognita at 5 days after inoculation. N: infecting nematodes, Arrows: necrotic areas, G: giant cell, X: xylem vessel. Bars $=20 \mu \mathrm{m}$.

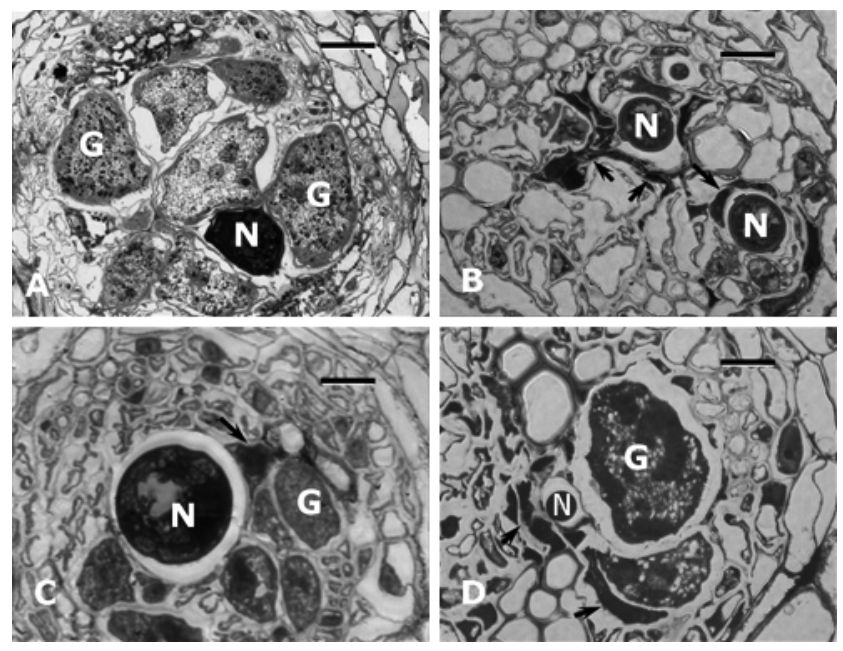

Fig. 3. Light micrographs of susceptible and resistant responses in chili peppers (A: Chilseongcho, B: CM334, C: 02G132, D: 03G53) infected with Meloidogyne incognita at 10 days after inoculation. N: infecting nematodes, Arrows: necrotic areas, G: giant cell, Xy: xylem vessel. Bars $=20 \mu \mathrm{m}$.

(Fig. 3A). In CM334, no giant cell but extensive necrosis was formed around the infecting nematodes (Fig. 3B). In 02G132 and 03G53, however, giant cells were formed and also necrotic responses around giant cells and infecting nematodes were observed (Fig. 3C, D). Unlike the giant cells in the susceptible pepper Chilseongcho, these giant cells appeared to be degenerated at the developing stages of the nematode, characterized by giant cell cytoplasm stained dark blue with disorganized appearances.

\section{Discussion}

In our study, out of 39 chili pepper cultivars/lines tested for resistance and susceptibility, 6 were determined to be resistant to $M$. incognita infection, showing no or very few gall formations (gall index $<\mathrm{GI}>$ less than 1.0), which are the main symptoms characteristic to the root-knot nematode infections. Nematode penetrations occurred in 3 resistant pepper cultivar/lines tested, including cv. CM334, Ls. 02G132 and 03G53, but significantly lowered compared to the susceptible pepper cv. Chilseongcho. No nematode reproduction occurred in the three resistant pepper plants, suggesting that the nematodes penetrating the resistant plant roots were further inhibited in their growth and development. It was suggested in soybean (Dropkin and Nelson, 1960), cotton (Anwar and Mckenry, 2000) and pepper (Pegard and Brizzard, 2005) that the failure of J2 in penetrating roots of resistant cultivars/lines may be related with physical or chemical root barriers. Resistant plant roots have an effect of nematostasis on Meloidogyne J2 (Hayne and Jones, 1976; Pegard and Brizzard, 2005; Tanda et al., 1989). In Phytophthora blight of chili pepper caused by Phytophthora capsici, the pathogen penetration and infection appear to be blocked by root exudation materials accumulated on the root surface and by thickened middle lamellae between the epidermal and cortical cells (Kim and Kim, 2009).

In cv. Chilseongcho, extensive giant cells were formed by M. incognita in the stele of the swollen roots (galls). $M$. incognita-induced galls and giant cells may provide parasites with the energy they need for invading plant roots (Shepherd and Huck, 1989). In the highly resistant CM334, no giant cell was formed with extensive necrosis responses, which are considered as the hypersensitive responses (HR) that can be seen with naked eyes or with the microscope (Agrios, 2005). In the other two resistant pepper lines (02G132 and 03G53), giant cells were formed but necrotic responses (HR) were also prominent, which appeared to inhibit the further development of giant cells or accelerate their degeneration. Therefore, the inhibition of nematode growth and development after penetration may be related to the inhibited formation and development of giant cells that nurse the infecting root-knot nematodes (Jones, 1981).

In the resistance of potato to the root-knot nematode, the incompatibility responses are characterized by penetration of fewer J2 into roots, necrosis of feeding sites within 2-7 days, and lack of nematode development (Canto-Saenz and Brodie, 1987). Our study also showed less J2 penetration, early necrosis in feeding sites and retarded nematode development as resistance responses in the resistant pepper cultivar/lines, which differed significantly in the degree of 
the resistance responses. In CM334, the nematode penetration rate was highest among the three resistant pepper cultivar/lines, but the necrosis formation in the infection sites was most extensive with no giant cell formation, which probably made this pepper cultivar highly resistant. In comparison of the two resistant pepper lines $02 \mathrm{G} 132$ and 03G53, the extension of necrosis formation was similar between the two lines, but the nematode penetration rate was significantly lower in 03G653 than 02G132, which might lead their host status to be highly resistant and resistant, respectively. The host resistance and susceptibility is known to be genetically controlled; the differences in structural modifications of root tissues infected with the root-knot nematode may reflect genetic differences between the susceptible and resistant peppers and also among the resistant peppers.

In conclusion, the results showed diverse mechanisms of resistance in the roots of nematode-resistant pepper cultivars/lines. The histopathological modifications after the nematode penetration suggest the disease resistance may be more of post-infectional rather than pre-infectional defense mechanisms. In addition, these histological differences of pepper resistant cultivars/lines, a reflection of genetic differences, may provide relevant information about the biological relationships between the nematode infection and host responses to elucidate variations of resistance in plants to the nematode infections.

\section{References}

Agrios, G. N. 2005. Plant Pathology, Fifth edition. Academic Press, San Diego, CA. 922 pp.

Anwar, S. A. and McKenry, M. V. 2000. Penetration, development and reproduction of Meloidogyne arenaria on two new resistant Vitis spp. Nematropica 30:9-17.

Barker, K. 1998. Introduction and synopsis of advancements in nematology. In: Plant Nematode Interactions, ed. by K. R. Barker, G A. Pederson and G. L. Windham, pp. 1-20. American Society of Agronomy, Crop Science Society of America, Soil Science Society of America, Madison, WI.

Canto-Saenz, M. and Brodie, B. B. 1987. Comparison of compatible and incompatible response of potato to Meloidogyne incognita. J. Nematol. 19:218-221.

Dropkin, V. H. and Nelson, P. E. 1960. The histopathology of root-knot nematode infections in soybeans. Phytopathology $50: 442-447$.

Hartman, K. M. and Sasser, J. N. 1985. Identification of Meloidogyne species on the basis of differential host test and perennial-pattern morphology. In: An Advanced Treatise on Meloidogyne, Volume 11: Methodology, ed. by K. R. Barker, C. C. Carter and J. N. Sasser, pp. 69-78. North Carolina State University Graphics, Raleigh, NC.

Hayne, R. L. and Jones, C. M. 1976. Effects of the Bi locus in cucumber on reproduction, attraction, and response of the plant to the southern root knot nematode. J. Am. Soc. Hortic. Sci. 101:422-424.

Jones, M. G K. 1981. Host cell responses to endoparasitic attack: structure and function of giant cells and syncytia. Ann. Appl. Biol. 97:353-72.

Kaplan, D. T. and Keen, N. T. 1980. Mechanisms conferring plant incompatibility to nematodes. Rev. Nématol. 3:123-134.

Khan, Z., Kim, S. G, Jeon, Y. H., Khan, H. U., Son, S. H. and Kim, Y. H. 2008. A growth promoting rhizobacterium, Paenibacillus polymyxa strain GBR-1, suppresses root-knot nematode. Biores. Technol. 3016-3023.

Kim, S. G. and Kim, Y. H. 2009. Histological and cytological changes associated with susceptible and resistant responses of chili pepper root and stem to Phytophthora capsici infection. Plant Pathol. J. 25:113-120.

Kim, Y. H., Riggs, R. D. and Kim, K. S. 1986. A mechanism of density dependent population change in Heterodera glycines. Korean J. Plant Pathol. 2:199-206.

Oka, Y., Koltai, H., Bar-Eyal, M., Mor, M., Sharon, E., Chet, I. and Spiegel, Y. 2000. New strategies for the control of plantparasitic nematodes. Pest Management Sci. 56:983-988.

Paulson, R. E. and Webster, J. M. 1972. Ultrastructure of the hypersensitive reaction in roots of tomato, Lycopersicon esculentum L., to infection by the root-knot nematode, Meloidogyne incognita. Physiol. Plant Pathol. 2:227-234.

Pegard, A. and Brizzard, G 2005. Histological characterization of resistance to different root-knot nematode species related to phenolics accumulation in Capsicum annuum. Nematology 95:158-165.

Pontier, D., Gan, S. S., Amasino, R. M., Roby, D. and Larn, E. 1999. Markers for hypersensitive response and senescence show distinct patterns of expression. Plant Mol. Biol.39:12431255.

Sasser, J. N. 1977. Worldwide dissemination and importance of the root knot nematode, Meloidogyne spp. J. Nematol. 22:585589.

Sasser, J. N., Carter, C. C. and Hartman, K. M. 1984. Standardization of host suitability studies and reporting of resistance to root-knot nematodes. Crop Nematode Res. Control Proj., NCSU/USAID. Dept. of Plant Pathol., NCSU, Box 7616, Raleigh, North Carolina 27695, USA. 7 pp.

Shepherd, R. L. and Huck, M. G 1989. Progression of root-knot nematode symptoms and infection on resistant and susceptible cottons. J. Nematol. 21:235-241.

Southey, J. F. 1986. Laboratory Methods for Work with Plant and Soil Nematodes. Ministry of Agriculture Fisheries and Food, HMSO, London, UK.

Spurr, A. R. 1969. A low viscosity epoxy resin embedding medium for electron microscopy. J. Ultrastr. Res. 26:31-43.

Tanda, A. S., Atwal, A. S. and Bajaj, Y. P. S. 1989. In vitro inhibition of root-knot nematode Meloidogyne incognita by sesame root-exudate and its amino acids. Nematologica 35:115-124.

Taylor, A. L. and Sasser, J. N. 1978. Biology, Identification and Control of Root-knot Nematodes, Meloidogyne Species. International Meloidogyne Project, Department of Plant Pathology, North Carolina State University and the U.S. Agency for International Development, Raleigh, North Carolina, U.S.A. 111 pp. 